\title{
Upper gastrointestinal bleeding due to mixed adenoneuroendocrine carcinoma and radiation esophagitis treated with cap-mucosectomy combined with radiofrequency ablation
}

The management of upper gastrointestinal bleeding is standardized according to European Society of Gastrointestinal Endoscopy guidelines [1]. Telangiectasias due to radiation esophagitis are classically managed with argon plasma coagulation (APC) [2,3]. Radiological or surgical management is proposed when APC treatment fails with ongoing bleeding due to radiation esophagitis. Mixed adenoneuroendocrine carcinoma (MANEC) is a rare complication of Barrett's esophagus [4]. Endoscopic resection of localized MANEC can be performed, whereas in cases of extensive MANEC, chemotherapy and radiotherapy are indicated. Recently, radiofrequency ablation (RFA) has been used to treat Barrett's esophagus with low or high grade dysplasia without visible lesions [5]. RFA allows cicatrization scarification of esophageal mucosa without recurrence of Barrett. We report a case of chronic esophageal bleeding due to recurrent MANEC combined with radiation-induced telangiectasias, treated successfully with the combination of cap-mucosectomy and RFA.

A 77-year-old man presented with recurrent upper gastrointestinal bleeding that required blood transfusion. He was treated for MANEC on Barrett's esophagus with chemotherapy and radiotherapy. Upper endoscopy showed a bleeding flat lesion associated with oozing from radiation-induced telangiectasia ( Fig.1 a,b). APC was performed without success. Combined treatment with cap-mucosectomy and RFA was proposed to treat upper gastrointestinal bleeding ( $>$ Video 1 ).

The 0 -Ila lesion was resected using capmucosectomy with a hot asymmetric snare ( $\triangleright$ Fig. 1 c). During the same procedure, RFA using a $360^{\circ}$ catheter was applied to the telangiectasias ( $\triangleright$ Fig. $1 \mathbf{d}$ ). No adverse events occurred. Histologi-


- Fig. 1 Upper gastrointestinal bleeding. a Oozing telangiectasias. b Spontaneous bleeding of a flat 0-lla lesion on Barrett's esophagus. c Scar after cap-mucosectomy. d Application of circumferential radiofrequency ablation on telangiectasias.

cal examination showed a recurrence of MANEC and chemotherapy was started. At 3 months, upper endoscopy showed no recurrence of telangiectasias ( $\triangleright$ Fig.2), some Barrett's islands, and a benign esophageal stricture without clinical signs. Hemoglobin remained stable without blood transfusion.

This case highlights a new utilization of RFA to treat recurrent bleeding from radiation esophagitis. Esophageal stricture seems to be the main adverse event when treating Barret's esophagus with high grade dysplasia.

Endoscopy_UCTN_Code_TTT_1AO_2AD

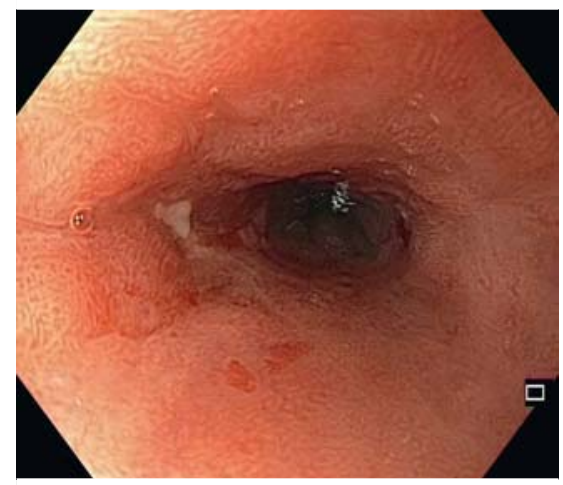

Fig. 2 Endoscopy 3 months after combined cap-mucosectomy and radiofrequency ablation showed substenosis of the esophagogastric junction without recurrence of telangiectasias. 


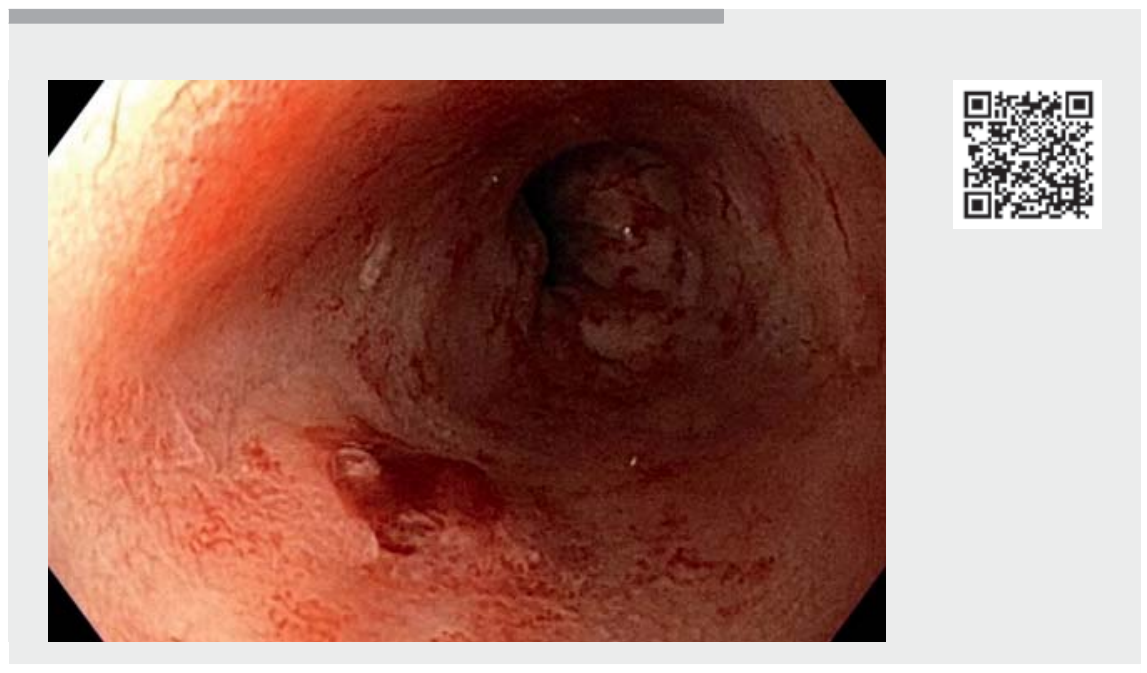

$\checkmark$ Video 1 Endoscopic management of upper gastrointestinal bleeding due to recurrence of esophageal mixed adenoneuroendocrine carcinoma and radiation-induced telangiectasias.

\section{Competing interests}

The authors declare that they have no conflict of interest.

The authors

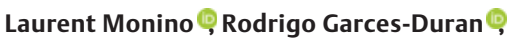

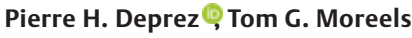
Department of Hepatogastroenterology, Université catholique de Louvain, Cliniques universitaires Saint-Luc, Brussels, Belgium

\section{Corresponding author}

\section{Laurent Monino, MD}

Department of Hepatogastroenterology,

Cliniques universitaire Saint Luc, UC Louvain, Ave Hippocrate 10,1200 Brussels, Belgium laurent.monino@uclouvain.be monino.laurent@hotmail.fr

\section{References}

[1] Gralnek IM, Stanley AJ, Morris A] et al. Endoscopic diagnosis and management of nonvariceal upper gastrointestinal hemorrhage (NVUGIH): European Society of Gastrointestinal Endoscopy (ESGE) Guideline - Update 2021. Endoscopy 2021; 53: 300-332

[2] Afifi ANAM, Powerski M, Jechorek D et al. Radiation-induced damage in the upper gastrointestinal tract: clinical presentation, diagnostic tests and treatment options. Best Pract Res Clin Gastroenterol 2020; 48-49: 101711

[3] Andreyev HJN, Davidson SE, Gillespie C et al. Practice guidance on the management of acute and chronic gastrointestinal problems arising as a result of treatment for cancer. Gut 2012; 61: 179-192

[4] Kawazoe T, Saeki H, Edahiro K et al. A case of mixed adenoneuroendocrine carcinoma (MANEC) arising in Barrett's esophagus: literature and review. Surg Case Rep 2018; 4: 45

[5] Weusten BLAM, Bisschops R, Coron E et al. Endoscopic management of Barrett's esophagus: European Society of Gastrointestinal Endoscopy (ESGE) position statement. Endoscopy 2017; 49: 191-198
Bibliography

Endoscopy 2022; 54: E308-E309

DOI 10.1055/a-1516-3816

ISSN 0013-726X

published online 9.7.2021

(C) 2021. Thieme. All rights reserved.

Georg Thieme Verlag KG, Rüdigerstraße 14, 70469 Stuttgart, Germany

\section{ENDOSCOPY E-VIDEOS}

https:/|eref.thieme.de/e-videos

口局 Endoscopy E-Videos is an Fin open access online section, 自嗮: reporting on interesting cases and new techniques in gastroenterological endoscopy. All papers include a high quality video and all contributions are freely accessible online. Processing charges apply (currently EUR 375), discounts and wavers acc. to HINARI are available.

This section has its own submission website at https://mc.manuscriptcentral.com/e-videos 